\title{
Artificial Disc Insertion Following Anterior Cervical Discectomy
}

\author{
Gwynedd E. Pickett, Neil Duggal
}

\begin{abstract}
Objective and importance: Fusion following anterior cervical discectomy has been implicated in the acceleration of degenerative changes in the adjacent spinal segments. Discectomy followed by implantation of an artificial cervical disc maintains the functionality of the spinal unit, while still providing excellent symptomatic relief. We describe our preliminary experience with implantation of the Bryan Cervical Disc System in two cases of single-level cervical disc herniation. Clinical presentation: Two male patients presented with a left C6 radiculopathy, without evidence of myelopathy. Magnetic resonance imaging revealed a disc herniation at C5-6 in both cases. Pre-operative flexion and extension radiographs demonstrated preserved motion at the involved levels. Intervention/technique: Following a standard anterior cervical decompression, precision drilling of the vertebral endplates was carried out using a drill attached to a bed-mounted, gravitationally-referenced retraction frame. An artificial cervical disc, composed of a polyurethane nucleus with titanium endplates, was fitted between the contoured endplates without fixation to the vertebral bodies. No complications were experienced during the insertion of the prosthesis, or in the postoperative course. Both patients experienced immediate postoperative resolution of their radicular pain and were discharged from hospital the following day. At nine months following surgery, both patients continue to have complete relief of radicular symptoms. Postoperative radiographs at six months following surgery confirm accurate placement of the prosthesis and preserved mobility of the functional spinal unit. Conclusion: Insertion of the Bryan artificial cervical disc prosthesis following anterior cervical discectomy is a relatively straightforward procedure, which appears to be safe and provides good clinical results, without requiring additional surgical time. Longterm follow-up is required to assess its safety, efficacy, and ability to prevent adjacent segment degeneration.
\end{abstract}

RÉSUMÉ: Insertion d'un disque artificiel suite à une discectomie cervicale antérieure. Objectif et importance: Il semble qu'une fusion vertébrale suite à une discectomie cervicale antérieure puisse accélérer les changements dégénératifs au niveau des segments spinaux adjacents. La discectomie suivie de l'implantation d'un disque artificiel maintient la fonction du segment spinal tout en assurant un excellent soulagement des symptômes. Nous décrivons notre expérience d'implantation du Bryan Cervical Disc System chez deux cas de hernie discale cervicale. Étude de cas: Il s'agit de deux patients présentant une radiculopathie C6 gauche sans manifestation de myélopathie. L'imagerie par résonance magnétique a montré une hernie discale au niveau de C5-C6 dans les deux cas. Des radiographies prises en flexion et en extension avant la chirurgie ont montré une amplitude de mouvement normale à ces niveaux. Technique opératoire: Après décompression cervicale antérieure par la technique standard, les plateaux vertébraux ont été préparés au moyen d'une aléseuse. Un disque cervical artificiel composé d'un noyau de polyuréthane avec des plateaux en titanium a été inséré entre les plateaux vertébraux profilés sans être fixé aux corps vertébraux, sans complication intra ou postopératoire. La douleur radiculaire est disparu immédiatement après la chirurgie et ils ont quitté l'hôpital le lendemain de la chirurgie. Neuf mois plus tard, aucun des deux patients n'a présenté de récidive de la douleur radiculaire. Des radiographies faites six mois après la chirurgie ont confirmé que la prothèse était en bonne position et que la mobilité de l'unité spinale fonctionnelle était préservée. Conclusions: L'insertion d'une prothèse de Bryan après une discectomie cervicale antérieure est une intervention relativement simple qui semble sûre et dont les résultats cliniques sont bons, sans toutefois prolonger l'intervention. Ces patients devront être suivis à long terme afin d'évaluer la sécurité, l'efficacité et l'influence de cette intervention sur la dégénérescence des segments adjacents.

Can. J. Neurol. Sci. 2003; 30: 278-283

Anterior cervical discectomy and fusion (ACDF) is a wellestablished, commonly performed surgical procedure for cervical spondylosis. Since its introduction by Robinson and Smith as well as Cloward in the $1950 \mathrm{~s},{ }^{1,2}$ excellent clinical results have been reported in the treatment of degenerative disorders of the cervical spine. ${ }^{3-9}$ Interbody fusion has, however, the disadvantage of converting a functionally mobile, mechanically stable spinal unit into a fixed, nonfunctional one. Analysis of strain distribution in intervertebral discs following ACDF has shown an increase in longitudinal strain, most commonly at levels immediately adjacent to the fused segment. ${ }^{10}$
The resultant increase in stress on discs adjacent to the fused level is thought to lead to accelerated disc degeneration and/or mechanical instability at adjacent levels. ${ }^{10-13}$ Radiographic changes of spondylosis and instability at levels above and below

From the Division of Neurosurgery, London Health Sciences Centre, London, Ontario, Canada.

Received SePtember 26, 2002. Accepted in final form February 24, 2003. Reprint requests to: Neil Duggal, London Health Sciences Centre, University Campus, 339 Windermere Rd., London, Ontario N6A 5A5 Canada. 
cervical fusions have been described by several authors, $5,8,11,13-15$ although have not always been associated with recurrent clinical symptoms. ${ }^{16-19}$ There is controversy as to whether these changes are attributable to the biomechanical effects of fusion or are simply the natural history of spondylosis in a patient susceptible to cervical disc disease.

The observed degeneration of cervical spinal units adjacent to a fusion has been termed adjacent segment disease (ASD). It may be particularly relevant in younger patients with active lifestyles, who possess a higher lifetime risk for further cervical disc degeneration. A retrospective survivorship analysis of 409 ACDF in 374 patients found that symptoms of radiculopathy and/or myelopathy referable to an adjacent level occurred at a relatively constant rate of $2.9 \%$ per year, with a projected survivorship rate of $26 \%$ at 10 years. ${ }^{12}$ In several long-term studies of patients treated with ACDF, up to $10 \%$ of patients have required re-operation at an adjacent level for new radiculopathy and/or myelopathy secondary to disc herniation or progressive

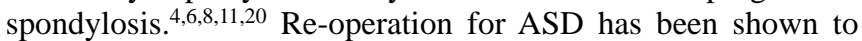
have decreased rates of arthrodesis and successful clinical outcomes: the presence of an adjacent solid fusion lessens the success rate of $\mathrm{ACDF}^{21}$

Understanding of biomechanics and biocompatible materials has led to the successful development of artificial joints, and interest has thus naturally arisen in the possible role of an artificial cervical disc for the treatment of degenerative cervical disease. Implantation of such a device following removal of the failed natural intervertebral disc eliminates the need for segmental fusion. It is theorized that by maintaining functional motion at the operated spinal unit, the accelerated degeneration of adjacent segment disease may be avoided. We describe our preliminary experience with insertion of a new cervical artificial disc, the Bryan Cervical Disc System (Spinal Dynamics, distributed by Medtronic Sofamor Danek, Memphis, TN), for the treatment of symptomatic radiculopathy in two patients.

\section{CASE RePort}

Two male patients, a 33-year-old electrician and a 46-year-old police officer, presented with left C6 radiculopathy refractory to conservative management. Neither patient had any evidence of myelopathy. Pain and sensory symptoms had been present in both patients for two to three years, but had progressively worsened over four months prior to surgery. Magnetic resonance imaging (MRI) confirmed C5-6 disc disease with left C6 nerve root compression in both patients, caused in one case by a soft disc herniation, and in the other by a combination of soft disc and osteophyte. Pre-operative lateral radiographs obtained in neutral, flexion and extension confirmed that motion was preserved at the C5-6 level (Figures $1 \mathrm{~A} \& \mathrm{~B}$ ). Neither patient had undergone spontaneous fusion at the affected level, nor was there evidence of instability or malalignment at that or other levels.

Informed consent was obtained from both patients to perform an ACD followed by insertion of the Bryan cervical disc prosthesis. This device consists of a polyurethane nucleus, surrounded by a polyurethane sheath, situated between two titanium alloy shells (Figure 2.) The bonecontacting surface of each shell is covered with a porous titanium coating to encourage bony ingrowth. The convex shells fit within concavities drilled into each vertebral body, securing the device once inserted. Anterior stops on each shell also guard against posterior migration of the disc. Saline is injected into the disc prior to insertion, providing lubrication and a degree of fluid resistance to compression.

Pre-operatively, computed tomography (CT) was employed to make accurate measurements of the anterior-posterior (AP) diameter of the C5-6 vertebral body endplates. These were used to determine the probable size of prosthesis to be inserted.

In each case, the patient was positioned supine on the operating table,
A

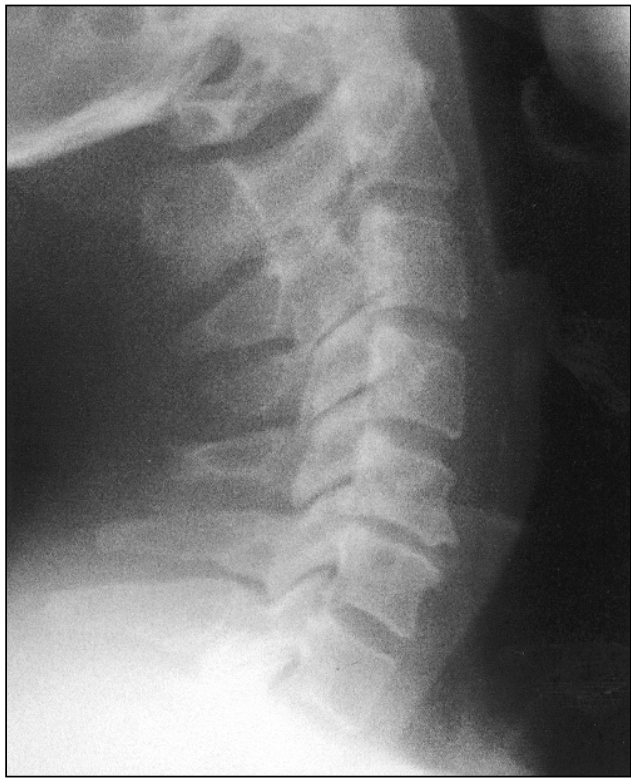

B

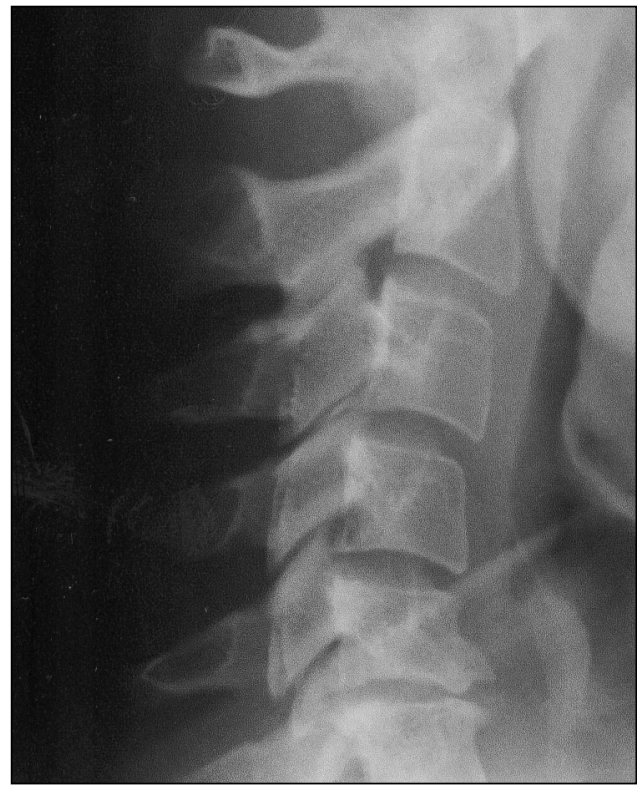

Figure 1: Preoperative lateral cervical radiographs in extension $(A)$ and flexion $(B)$ demonstrates preserved motion at C5-6, despite degenerative changes including decreased disc height, end-plate sclerosis, and osteophyte formation. 


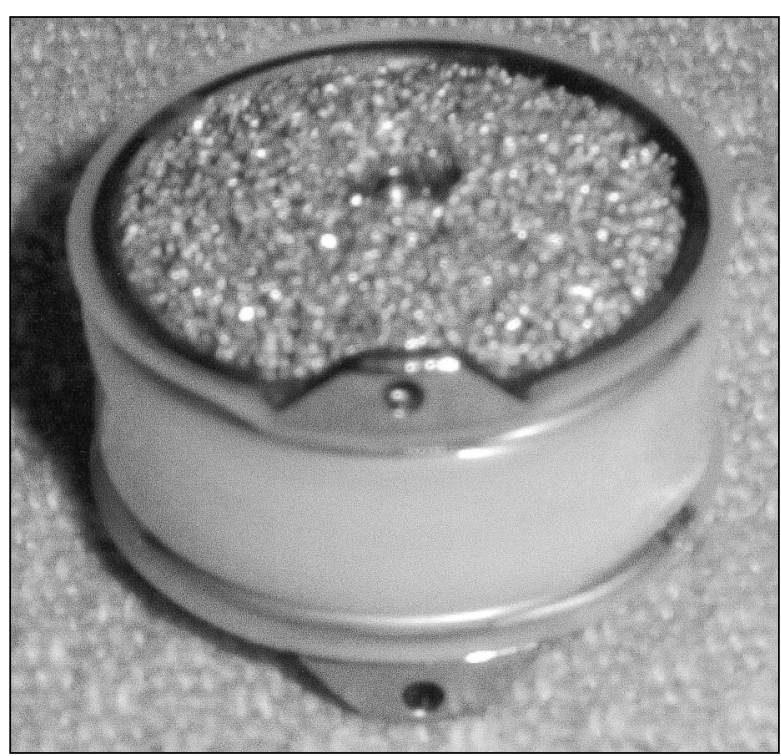

Figure 2: The cervical disc prosthesis consists of a flexible polyurethane nucleus bordered by porous titanium alloy end plates, designed to encourage bony ingrowth for long-term stability.

with the neck supported by a rolled towel, the head on a firm donut, and the chin elevated with tape. A standard transverse incision was made, but extended to $1 \mathrm{~cm}$ across the midline. Following exposure of the vertebral column the retractor system was assembled and centered over the target disc space. The discectomy was then carried out in the usual fashion with curettes and rongeurs. Complete posterior decompression with the operating microscope was deferred until after drilling of the endplates, to take advantage of a larger working space and easier visualization. Following the initial discectomy, drilling of the intervertebral disc space was performed using a gravitational referencing system to establish a virtual axis in space. The reference system was attached both to the bedmounted retraction frame, and also to temporary anchor screws placed in the vertebral bodies. Anchoring screws are used to ensure accurate positioning of the reference frame, which guides and controls the cutting instruments that prepare the vertebral endplates for placement of the prosthesis. The milled endplates match the external geometry of the implant, providing immediate AP and lateral stability. Measurements were taken at each stage of the drilling to confirm safety, positioning, and the appropriate size of the prosthesis chosen. Fluoroscopy was used to confirm the location of the drill and the extent of bone removal (Figure 3).

A spacer with convex ends matching the prosthesis measurements was then inserted into the disc space and left there a few moments while the drill system and much of the retractor frame was removed. The spacer provided some compaction against the bony endplates, and controlled much of the bleeding produced by drilling. A distractor was then applied, the spacer removed, and the operating microscope brought into place for decompression of the remaining disc and opening of the posterior longitudinal ligament. In one case, a large soft disc herniation was identified in the neural foramen; in the other, most of the compression was secondary to a left-sided osteophyte. With the decompression completed, the prosthesis was then inserted. Anterior-posterior and lateral fluoroscopy confirmed adequate positioning of the disc.

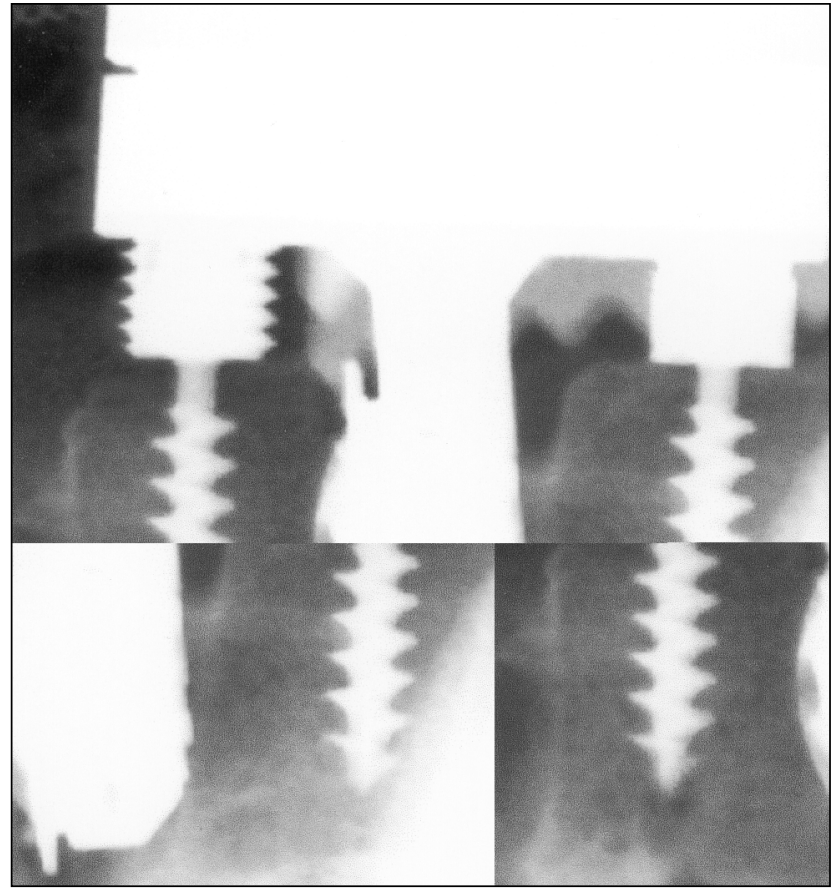

Figure 3: Lateral fluoroscopy confirms positioning of the drill during milling of the vertebral endplates. Screws in the vertebral body anchor the drilling apparatus to ensure a precise milling of the vertebral endplates.

Both patients experienced immediate postoperative relief of their radicular pain. They mobilized rapidly, and were discharged home the next day. No form of external immobilization was used. Neutral cervical radiographs were obtained on the first postoperative day, and at a threeweek return clinic visit (Figures $4 \mathrm{~A} \& \mathrm{~B}$ ), while flexion and extension radiographs were performed at three and six months following surgery (Figures 4C\&D). Disc height had been restored, spinal alignment was restored, and the prostheses had remained in their original position and orientation. At nine months following surgery, both patients have had excellent resolution of their symptoms.

\section{Discussion}

There is considerable controversy and disparity of opinion regarding the cause, incidence, and clinical importance of ASD. It is postulated that anterior cervical arthrodesis may alter the natural history of cervical spondylosis, hastening the degeneration of nonoperated spinal segments. Fusion of the cervical spine alters spinal biomechanics not only at the involved motion segment, but also at levels immediately above and below the fusion. Adjacent-level motion has been shown to increase by $15 \%$ at one year following arthrodesis, ${ }^{13}$ while biomechanical modeling has predicted increased intradiscal pressures in cervical discs adjacent to prior intervertebral fusions. ${ }^{22}$ This increased mechanical demand on mobile adjacent segments may lead to accelerated disc degeneration or mechanical instability. ${ }^{8,11-13}$ Long-term radiographic follow-up of patients with anterior cervical fusions has shown the development of hypermobility and degenerative changes, including disc space 

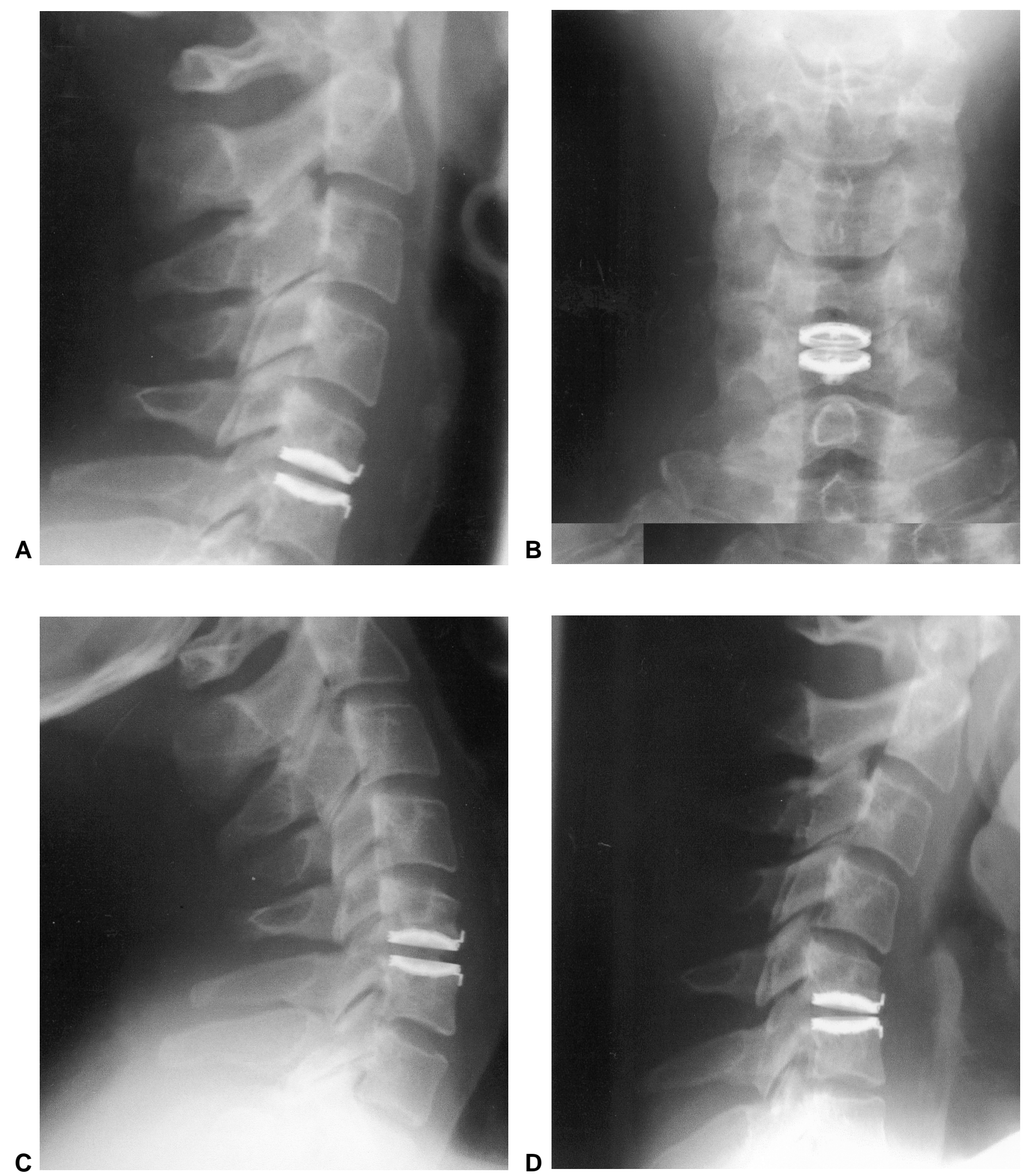

Figure 4: Lateral (A) and anterior-posterior (B) cervical radiographs of the same patient taken three weeks postoperatively confirms correct positioning of the prosthesis. At six months, dynamic views demonstrate preserved motion of the C5-C6 prosthesis in extension $(C)$ and flexion $(D)$. 
narrowing, end-plate sclerosis, and osteophyte formation, in the nonfused segments of the spine..$^{5,6,11,13,15}$ Reported rates of radiographic evidence of degeneration adjacent to ACDF range from 0 to $81 \%,{ }^{5,6,14,23}$ varying with length of follow-up and whether a control group was included.

The rate of clinically relevant ASD is also debated. Several authors have demonstrated radiographic evidence of degenerative changes, without clinical correlation. ${ }^{16-19}$ Most published series on ASD note that many of the degenerative changes observed radiographically are asymptomatic. However, Gore and Sepic $^{6}$ noted that patients with recurrent cervical pain were more likely to have experienced progression of spondylosis at the unfused levels, than were patients without recurrence. In a series of 110 patients treated for cervical myelopathy, 26.4\% developed recurrent clinical symptoms during a mean follow-up of six years. ${ }^{24}$ Again, however, rates vary widely in the literature, with $2.2 \%$ to $26 \%$ of patients reportedly experiencing neurological symptoms from ASD. ${ }^{6,68,11,12,20,21,24-26}$ The length of follow-up likely influences the reported rate of ASD, since symptoms recur at a relatively constant yearly rate and may appear up to 10 years following ACDF. ${ }^{12}$ Recurrent clinical symptoms are more likely when asymptomatic spondylotic changes were present in adjacent segments preoperatively. ${ }^{5}$

The motion of each spinal unit appears to be important in the development of ASD. Hilibrand et $\mathrm{al}^{18}$ found that the risk of ASD was most closely correlated to the predicted motion of that segment, with segments with a greater magnitude of motion having a greater incidence of ASD. A simulation of multi-level fusions in cadavers confirmed increased sagittal plane motion at the remaining open segments, but found that the percentage change in motion was uniform across all motion segments, not concentrated at adjacent levels. ${ }^{27}$ In other words, the absolute increase in motion varied depending on each segment's natural motion. C5-6 and C6-7, segments with naturally higher ranges of motion, have a higher relative risk of ASD. ${ }^{12}$ This suggests that the increased motion following fusion may have a causative role in producing or accelerating degeneration. Thus, maintenance of normal spinal motion following ACD, by insertion of a cervical prosthesis, may reduce the long-term risk of ASD.

Initial efforts at maintaining cervical motion following discectomy centered on placement of a ball-and-socket joint into the disc space, secured to the adjacent vertebral bodies by anterior plates and screws. ${ }^{13,28}$ Complications associated with these devices include inadequate screw placement, screw failure, dysphagia due to bulk of the anterior components, and joint subluxation. However, cervical vertebral motion was preserved in the majority of cases, and most patients experienced improvement in their symptoms. Furthermore, 12-month followup demonstrated that patients who received an artificial cervical joint had an overall reduction in adjacent level mobility, significantly different from the increased mobility observed in patients with ACDF. ${ }^{13}$

An alternative approach to the ball-and-socket joint involves replacing the excised cervical disc with an artificial disc. Such a prosthesis must mimic the motion and elasticity of the original disc, and provide for balanced and integrated motion of the spinal unit. It must possess maximum durability, biocompatibility, and a means of integrating itself into the spine for longterm stability. Its insertion should be safe, straightforward, and ideally should not add significantly to surgical time. Finally, its clinical success must match or surpass the excellent outcomes achieved by standard discectomy and one-level cervical arthrodesis. Pointillart ${ }^{29}$ recently published a report of the "first failure" of a cervical disc prosthesis; he reported that eight of 10 patients failed to maintain cervical mobility at the implant level, and the remaining two who had mobility also had severe neck pain.

Better results have been obtained with preliminary use of the Bryan cervical disc in Europe, in 97 patients. Recently published data indicate that of 30 patients followed for 12 months, $80 \%$ had an "excellent" clinical result, and $88 \%$ had preserved motion at the implant level. ${ }^{30}$ No device failures or explantations were recorded.

Examination of the Bryan artificial disc confirmed that it reproduces accurately the important characteristics of the native disc. It possesses elasticity, compressibility, and allows for semirestrained motion and translation. It is, however, rotationally unconstrained. The fit between the milled concavities and the convex outer shells of the disc is sufficient to provide immediate $\mathrm{AP}$ and lateral stability, obviating the need to fix the implant to one or both of the vertebral bodies. In reporting on the failure of a previous cervical disc model, Pointillart ${ }^{29}$ commented that such fixation may have triggered osteogenesis in the periosteum of the vertebral bodies, resulting in the high rate of endplate or circumferential fusion that he observed. The geometrical securing of the disc used in these cases may avoid this delayed complication, while preventing the alternative complication of disc migration.

The life expectancy of this prosthesis is unknown. It will only be properly determined from long-term follow-up of a large series of patients. Issues of disc settling or migration, wear debris affecting the disc function or producing systemic effects, and ongoing flexibility and durability of the polyurethane nucleus and sheath must be assessed. The potential for leakage of the saline lubricant and its impact on the functioning and mobility of the disc is of potential concern. This will ultimately be determined by the durability and life expectancy of the polyurethane sheath. Most importantly, there is no benefit in preventing re-operation for adjacent segment disease if, for example, the prostheses themselves require replacement or revision in 10 years.

One major potential complication that may be associated with insertion of this prosthesis results from the technique of preparing the vertebral endplates, which involves drilling without direct vision. Disc space drilling is performed using calibrated tools and the secured reference frame, but nonetheless the risk of vertebral artery or spinal cord injury exists. Careful analysis of the preoperative CT is recommended, both to determine the appropriate size of prosthesis, and to assess any anatomical abnormalities, including the position of the vertebral arteries. Intraoperative fluoroscopy is also recommended, to confirm throughout the procedure that alignment, reference points, and drilling margins are accurate.

For placement of an artificial cervical joint to be practical, the instrumentation required must not be excessively complex. We found the system to be straightforward and easy to learn, and the bed-mounted reference frame provided excellent retraction. The European experience suggests that insertion of the artificial disc 
takes less time than ACDF with iliac autograft and plating, ${ }^{30}$ and has the additional benefit of avoiding the morbidity associated with the iliac donor site.

Patients presenting with cervical radiculopathy and/or myelopathy, with radiological evidence of neural compression by osteophyte or herniated disc material, and with retained spinal motion at the level in question, may be considered for placement of an artificial cervical disc. Young patients, who have a high lifetime risk of adjacent segment disease, are suitable candidates for the prosthesis. The presence of asymptomatic spondylotic changes at other spinal levels need not preclude the use of an artificial disc; indeed, such patients are likely at increased risk of developing adjacent segment disease ${ }^{4}$ and avoidance of postfusion stresses at those levels may be of increased importance. The artificial disc may also be indicated for patients who have previously undergone an ACDF and present with a new radiculopathy and/or myelopathy secondary to a degenerative disc at an adjacent level.

The Bryan Cervical Disc System provides an effective and technically straightforward method to treat single level degenerative disc disease in the cervical spine. Immediate clinical results have been very satisfying in these two patients. Long-term follow-up of larger numbers of patients will be required to verify the prolonged safety and stability of the prostheses, and to confirm that the involved spinal segments maintain functional mobility. A clinical trial, soon to be undertaken in North America, will provide further information as to the long-term clinical and economic outcomes, determining in particular whether an artificial cervical disc can prevent or decrease the rate of adjacent segment disease while providing clinical results comparable to those of arthrodesis.

\section{ACKNOWLEDGMENT}

We thank Pat Doyle-Pettypiece, Mary-Lou Gough, and all members of the operating room staff for their professional assistance.

Neither author has any financial interest in the manufacture or distribution of the Bryan Cervical Disc System, nor any affiliation with Spinal Dynamics or Medtronic Sofamor Danek.

\section{REFERENCES}

1. Cloward RB. The anterior approach for removal of ruptured cervical discs. J Neurosurg 1958;15:602-617.

2. Robinson RA, Smith GW. Anterolateral cervical disc removal and interbody fusion for cervical disc syndrome. Bull Johns Hopkins Hosp 1955;96:223-224.

3. Bose B. Anterior cervical fusion using Caspar plating: analysis of results and review of the literature. Surg Neurol 1998;49:25-31.

4. Clements DH, O'Leary PF. Anterior cervical discectomy and fusion. Spine 1990;15:1023-1025.

5. DePalma AF, Rothman RH, Lewinnek GE, Canale ST. Anterior interbody fusion for severe cervical disc degeneration. Surg Gynecol Obstet 1972;134:755-758.

6. Gore DR, Sepic SB. Anterior cervical fusion for degenerated or protruded discs: a review of one hundred forty-six patients. Spine 1984;9:667-671.

7. Jacobs B, Krueger EG, Leivy DM. Cervical spondylosis with radiculopathy: results of anterior discectomy and interbody fusion. JAMA 1970;211:2135-2139.

8. Lunsford LD, Bissonette DJ, Janetta PJ, Sheptak PE, Zorub DS. Anterior surgery for cervical disc disease. Part 1: Treatment of lateral cervical disc herniation in 253 cases. J Neurosurg 1980;53:1-11.
9. Smith GW, Robinson RA. The treatment of certain cervical spine disorders by anterior removal of the intervertebral disc and interbody fusion. J Bone Joint Surg 1958;40A:607-623.

10. Matsunaga S, Kabayama S, Yamamoto T, et al. Strain on intervertebral discs after anterior cervical decompression and fusion. Spine 1999;24:670-675.

11. Baba $\mathrm{H}$, Furusawa $\mathrm{N}$, Imura $\mathrm{S}$, et al. Late radiographic findings after anterior cervical fusion for spondylotic myeloradiculopathy. Spine 1993;18:2167-2173.

12. Hilibrand AS, Carlson GD, Palumbo M, Jones PK, Bohlman HH. Radiculopathy and myelopathy at segments adjacent to the site of a previous anterior cervical arthrodesis. J Bone Joint Surg (Am) 1999;81:519-528.

13. Wigfield C, Gill S, Nelson R, et al. Influence of an artificial cervical joint compared with fusion on adjacent-level motion in the treatment of degenerative cervical disc disease. J Neurosurg 2002;(Spine 1) 96:17-21.

14. Gore DR, Gardner GM, Sepic SB, Murray MP. Roentgenographic findings following anterior cervical fusion. Skeletal Radiol 1986; 15:556-559.

15. Wu W, Thuomas KA, Hedlund R, Leszniewski W, Vavruch L. Degenerative changes following anterior cervical discectomy and fusion evaluated by fast spin-echo MR imaging. Acta Radiol 1996;37:614-617.

16. Cherubino P, Benazzo F, Borromeo U, Perle S. Degenerative arthritis of the adjacent spinal joint following anterior cervical spinal fusion: clinicoradiologic and statistical correlations. Ital J Orthop Trauma 1990;16:533-543.

17. Dohler JR, Kahn MR, Hughes SP. Instability of the cervical spine after anterior interbody fusion. A study on its incidence and clinical significance in 21 patients. Arch Orth Trauma Surg 1985; 104:247-250.

18. McGrory BJ, Klassen RA. Arthrodesis of the cervical spine for fractures and dislocations in children and adolescents. A longterm follow-up study. J Bone Joint Surg Am 1994;76:1606-1616.

19. Hunter LY, Braunstein EM, Bailey RW. Radiographic changes following anterior cervical fusion. Spine 1980;5:399-401.

20. Bohlman HH, Emery SE, Goodfellow DB, Jones PK. Robinson anterior cervical discectomy and arthrodesis for cervical radiculopathy. Long-term follow-up of one hundred and twentytwo patients. J Bone Joint Surg Am 1993;75:1298-1307.

21. Hilibrand AS, Yoo JU, Carlson GD, Bohlman HH. The success of anterior cervical arthrodesis adjacent to a previous fusion. Spine 1997;22:1574-1579.

22. Kumaresan S, Yoganandan N, Pintar F. Finite Element analysis of anterior cervical interbody fusion. Bio Med Mat Eng 1997; 7:221-230.

23. Goffin J, van Loon J, Van Calenbergh F, Plets C. Long-term results after anterior cervical fusion and osteosynthetic stabilization for fractures and/or dislocations of the cervical spine. J Spinal Disord 1995;8:500-508.

24. Yonenobu K, Okada K, Fuji T, et al. Causes of neurologic deterioration following surgical treatment of cervical myelopathy. Spine 1986;11:818-823.

25. Emery SE, Bohlmann HH, Bolesta MJ, Jones PK. Anterior cervical decompression and arthrodesis for the treatment of cervical spondylotic myelopathy. Two to seventeen-year follow-up. J Bone Joint Surg Am 1998; 80:941-951.

26. Geisler FH, Caspar W, Pitzen T, Johnson TA. Reoperation in patients after anterior cervical plate stabilization in degenerative disease. Spine 1998;23:911-920.

27. Fuller DA, Kirkpatrick JS, Emery SE, et al. A kinematic study of the cervical spine before and after segmental arthrodesis. Spine 1998;23:1649-1656.

28. Cummins BH, Robertson JT, Gill SS. Surgical experience with an implanted artificial cervical joint. J Neurosurg 1998;88:943-948.

29. Pointillart V. Cervical disc prosthesis in humans: first failure. Spine 2001;26:E90-E92.

30. Goffin J, Casey A, Kehr P, et al. Preliminary clinical experience with the Bryan Cervical Disc Prosthesis. Neurosurgery 2002;51:840-847. 